\title{
IMITATION MODELING OF AN INTER-TURN SHORT CIRCUIT OF AN ASYNCHRONOUS MOTOR STATOR WINDING FOR DIAGNOSTICS OF AUXILIARY ELECTRIC DRIVES OF TRANSPORT INFRASTRUCTURE
}

\author{
Sergey Goolak ${ }^{1}$, Juraj Gerlici², Oleg Gubarevych ${ }^{3, *}$, Tomáš Lack², Mikhail Pustovetov ${ }^{4}$ \\ ${ }^{1}$ Department of Traction Rolling Stock, State University of Infrastructure and Technologies, Kyiv, Ukraine \\ ${ }^{2}$ Department of Transport and Handling Machines, Faculty of Mechanical Engineering, University of Zilina, Zilina, \\ Slovakia \\ ${ }^{3}$ Department of Navigation and Operation of Technical Systems on Water Transport, Danube Institute of Water Transport, \\ State University of Infrastructure and Technologies, Kyiv, Ukraine \\ ${ }^{4}$ Department of Engineering Technology, Technological Institute (Branch) of Don State Technical University in the City of \\ Azov, Azov, Russia \\ *E-mail of corresponding author: oleg.gbr@ukr.net
}

\begin{abstract}
Resume
A scientific approach to calculating the parameters and characteristics of an asynchronous motor in the inter-turn short circuit mode in one phase of the stator is proposed to create the foundations of a diagnostic complex for assessing the condition of asynchronous motors of the transport infrastructure. This approach consists of the fact that in the model with which the research is carried out, it is proposed to take into account changes in the mutual inductance of the motor when the $\mathrm{AC}$ impedance of one of the stator phases changes. Using a new approach to modeling processes occurring in an asynchronous motor during the inter-turn short circuit in one phase of the stator, pulsations of the torque on the motor shaft were studied for different values of the AC impedance and resistance of one of the stator winding phases, which corresponds to varying degrees of the inter-turn short circuits.
\end{abstract}

Available online: https://doi.org/10.26552/com.C.2021.2.C65-C74

\section{Article info}

Received 12 May 2020

Accepted 6 November 2020

Online 3 March 2021

\section{Keywords:}

transport infrastructure, asynchronous motor, inter-turn short circuit, phase currents, torque ripple

ISSN 1335-4205 (print version) ISSN 2585-7878 (online version)

\section{Introduction}

For each state, development and creation of advanced transport infrastructure is a priority task that characterizes the level of economic development of the country.

The operational efficiency and development of other industries depends on efficiency of transport, especially its main types of rail and water transportation.

Ensuring efficient and highly profitable operation of transport is possible by increasing the reliability of its operation, which is ensured by the continuous development and improvement of diagnostic methods of operational control to establish the current status and predict the period of trouble-free operation.

Railway, as well as water transport, as auxiliary equipment incorporates a large number of asynchronous motors with squirrel-cage rotor of various powers. The simplicity of design and the reliability of asynchronous motors implied a high level of reliability of auxiliary electric drives in transport. This principle was laid down in design of a number of electric locomotives, as evidenced by lack of monitoring the asynchronous auxiliary machines status.

However, during the operation of these motors, a number of malfunctions can occur. These malfunctions can affect drive performance and make it partially or completely incapable to complete the process tasks.

Ensuring high-quality performance by the drive of the technological process is impossible without creation of modern diagnostic systems, both built-in (as part of the drive) and bench.

To build diagnostic systems, the choice of a diagnostic method is relevant. That choice requires an integrated approach to study of processes occurring in an asynchronous motor in the event of a malfunction. The purpose of this approach to the choice of diagnostic method is to study influence of the studied defect on the motor characteristics and determine the parameters by which the diagnosis will be performed.

An analysis of malfunctions of asynchronous motors, performed in [1-3], showed that about $15 \%$ of the total numbers of malfunctions of an asynchronous motor are associated with inter-turn short circuit of the 
stator windings. Thus, an integrated approach to study of processes occurring in an asynchronous motor when an inter-turn short circuit occurs is an urgent task.

\section{Methods for studying processes \\ in an asynchronous motor in the event of an inter-turn short circuit}

To effectively select the parameters by which the asynchronous motor diagnostics will be performed in order to determine the inter-turn short circuit in the stator windings, it is necessary to determine the design changes in the asynchronous motor caused by this defect. Studies conducted in [4-5] show that the inter-turn short circuit leads to asymmetrical modes in the stator winding. This is due to the fact that as a result of the inter-turn short circuit, both the resistant and inductive AC impedance's components of the phase, at which the circuit occurs, are reduced.

Study [6] showed that operation of an asynchronous motor with electric or magnetic asymmetry of the stator windings leads to an uneven distribution of losses in copper over the phases of the stator and appearance of variable components of the electromagnetic torque and power consumption. In [6], influence of the unbalance level of the phase currents on magnitude of the electromagnetic torque pulsations was not disclosed. The solution to this problem was investigated in [7-8]. In these works, it was shown that the unbalance of the stator phase currents leads to pulsations of the electromagnetic torque and the torque pulsations have a double frequency in comparison to frequency of the supply voltage.

Despite the fact that influence of the unbalance of the stator phase currents on the ripple of the electromagnetic torque was studied in [7-8], such questions as the effect of inter-turn short circuit on the active power consumed from the network and the power factor remain unresolved. These issues are considered in [9-10]. They noted that the interturn short circuit leads to an increase in the phase shift of the current relative to the voltage in all the three phases of asynchronous motors, which, in turn, leads to a decrease in the power factor. In addition, these works was shown that the inter-turn short circuit in the stator winding leads to an increase in the active power consumed by the motor from the network.

In the study, the effect of inter-turn short circuit on characteristics of an asynchronous motor should take into account a number of limitations associated with the quality of the motor supply voltage. Thus, in [11-12] it was noted that with a non-symmetrical power supply system, the voltage of the negative sequence causes pulsations of the electromagnetic torque in the motor with a stator, in which there is no inter-turn short circuit. The same effect is observed with a symmetrical system of voltages in the motor with inter-turn short circuit in the stator windings. In other words, in the presence of an asymmetrical power system, it will be difficult to identify the presence of inter- turn short circuit or its absence.

With a non-sinusoidal form of the supply voltage, higher harmonic components of the stator phase currents arise, which increase the loss of active power in the stator windings, it was noted in the studies [13-14]. These losses lead to a decrease in the power factor, which also makes it difficult to identify the presence or absence of inter-turn fault in the stator windings.

The proposed approach to study of effect of the interturn fault on the parameters and characteristics of an asynchronous motor consists in a comprehensive approach to the analysis of the influence of this defect on the parameters and characteristics of the motor, comparing the degree of change of different characteristics and parameters from the degree of inter-turn fault. The limitations adopted in the work relate to the power system of an asynchronous motor. They consist in the fact that the motor power system is symmetrical and the shape of the voltage is sinusoidal.

The results of this work can be used to select an effective method for constructing diagnostic circuits for asynchronous motors with short circuit rotor as part of the drive.

\section{The purpose and objectives of the study.}

The purpose of the study: the development of a simulation model and the study of diagnostic parameters during the inter-turn short circuit of the stator winding of an asynchronous motor, designed for operation as a part of auxiliary electric drives of the transport infrastructure.

To achieve this goal it is necessary to solve the following tasks:

- choose a mathematical model of an asynchronous motor that can work under the condition of asymmetry of the stator windings. On the selected model to realize the asymmetry of the stator windings caused by the circuit of the windings;

- $\quad$ to study effect of the inter-turn short circuit degree on one of the stator windings of the motor on the ripple factor of the electromagnetic torque and the unbalance of the stator phase currents;

- to study effect of the inter-turn short circuit degree on one of the stator windings of the motor on the mechanical and operational characteristics of the motor;

- $\quad$ perform a comparison for each parameter studied and each characteristics about the inter-turn short circuit degree on dynamics of changes in the main parameters and motor characteristics.

4 The choice of a model for the study of processes in an asynchronous motor in the event of an inter-turn short circuit

The object of research was a series squirrel-cage asynchronous motor model AIR132M $411.0 \mathrm{~kW}$, nameplate 
Table 1 Nameplate parameters of an asynchronous motor with a squirrel-cage rotor AIR132M4

\begin{tabular}{|c|c|c|c|}
\hline parameter & designation & unit & value \\
\hline shaft power rating & $P_{n}$ & $k W$ & 11.0 \\
\hline rated phase voltage & $U_{s}$ & $V$ & 220 \\
\hline rated frequency of supply voltage & $f_{s}$ & $H z$ & 50 \\
\hline rated rotation speed of a motor shaft in idle mode & $n_{\text {nidle }}$ & $r p m$ & 1500 \\
\hline no loadno-load torque & $T_{i d l e}$ & $N \cdot m$ & 0.38 \\
\hline stator winding resistance & $r_{1}$ & $\Omega$ & 0.5 \\
\hline resistance of the rotor winding reduced to the stator winding & $r_{2}^{\prime}$ & $\Omega$ & 0.36 \\
\hline stator winding reactance & $x_{1}$ & $\Omega$ & 0.56 \\
\hline rotor winding reactance reduced to stator winding & $x_{2}^{\prime}$ & $\Omega$ & 0.938 \\
\hline nominal motor shaft speed & $n_{n}$ & rpm & 1450 \\
\hline rated torque on the motor shaft & $T_{n}$ & $N \cdot m$ & 72.671 \\
\hline
\end{tabular}

parameters of which are given in the Table 1.

Research was carried out using the model of an induction motor given in [15-16]. In [16], a mathematical model of an induction motor, its implementation in the OrCAD software environment taking into account the magnetization curve from the main magnetic flux, are presented. Implementation of the mathematical model, taking into account the change in mutual inductance, when changing the $\mathrm{AC}$ impedance of one or more phase windings of the motor, is given in [15].

In [15] and [16], a mathematical model of an induction motor, recorded in the three-phase stator reference frame, is presented. Systems of equations, describing operation of the motor in these coordinates, have the form [15-16]:

$$
\left\{\begin{array}{c}
u_{s \alpha}=r_{s \alpha} \cdot i_{s \alpha}+\frac{d \psi_{s \alpha}}{d t} ; \\
u_{s \beta}=r_{s \beta} \cdot i_{s \beta}+\frac{d \psi_{s \beta}}{d t} ; \\
u_{s \gamma}=r_{s \gamma} \cdot i_{s \gamma}+\frac{d \psi_{s \gamma}}{d t} ; \\
-u_{r \alpha}=r_{r \alpha} \cdot i_{r \alpha}+\frac{d \psi_{r \alpha}}{d t}+\frac{\left(\psi_{r \beta}-\psi_{r \gamma}\right) \cdot p \cdot \omega_{r}}{\sqrt{3}} ; \\
-u_{r \beta}=r_{r \beta} \cdot i_{r \beta}+\frac{d \psi_{r \beta}}{d t}+\frac{\left(\psi_{r \gamma}-\psi_{r \alpha}\right) \cdot p \cdot \omega_{r}}{\sqrt{3}} ; \\
-u_{r \gamma}=r_{r \gamma} \cdot i_{r \gamma}+\frac{d \psi_{r \gamma}}{d t}+\frac{\left(\psi_{r \alpha}-\psi_{r \beta}\right) \cdot p \cdot \omega_{r}}{\sqrt{3}} ;
\end{array}\right.
$$

where:

$u$ - voltage, $V$;

$i$ - current, $A$;

$t$ - time, $S$;

$r$ - resistance, $\Omega$;

$\psi$ - flux linkage, $W b$;

$p$ - number of pole pairs;

subscripts $\alpha, \beta, \gamma$ mean belonging to the corresponding phase;

subscript $s$ - stator affiliation;

subscript $r$ - rotor affiliation;

$\omega_{r}$ - mechanical rotor speed, $r p m$;

Flux linkages are described by the following system of differential equations [15-16]:

$$
\left\{\begin{array}{l}
\psi_{s \alpha}=L_{s \alpha} \cdot i_{s \alpha}-0.5 \cdot M \cdot i_{s \beta}- \\
-0.5 \cdot M \cdot i_{s \gamma}+M \cdot\left(i_{r \alpha}-0.5 \cdot i_{r \beta}-0.5 \cdot i_{r \gamma}\right) ; \\
\psi_{s \beta}=L_{s \beta} \cdot i_{s \beta}-0.5 \cdot M \cdot i_{s \alpha}- \\
-0.5 \cdot M \cdot i_{s \gamma}+M \cdot\left(i_{r \beta}-0.5 \cdot i_{r \beta}-0.5 \cdot i_{r \gamma}\right) ; \\
\psi_{s \gamma}=L_{s \gamma} \cdot i_{s \gamma}-0.5 \cdot M \cdot i_{s \alpha}- \\
-0.5 \cdot M \cdot i_{s \beta}+M \cdot\left(i_{r \gamma}-0.5 \cdot i_{r \alpha}-0.5 \cdot i_{r \beta}\right) ; \\
\psi_{r \alpha}=L_{r \alpha} \cdot i_{r \alpha}-0.5 \cdot M \cdot i_{r \beta}- \\
-0.5 \cdot M \cdot i_{r \gamma}+M \cdot\left(i_{s \alpha}-0.5 \cdot i_{s \beta}-0.5 \cdot i_{s \gamma}\right) ; \\
\psi_{r \beta}=L_{r \beta} \cdot i_{r \beta}-0.5 \cdot M \cdot i_{r \alpha}- \\
-0.5 \cdot M \cdot i_{r \gamma}+M \cdot\left(i_{s \beta}-0.5 \cdot i_{s \beta}-0.5 \cdot i_{s \gamma}\right) ; \\
\psi_{r \gamma}=L_{r \gamma} \cdot i_{r \gamma}-0.5 \cdot M \cdot i_{r \alpha}- \\
-0.5 \cdot M \cdot i_{r \beta}+M \cdot\left(i_{s \gamma}-0.5 \cdot i_{s \alpha}-0.5 \cdot i_{s \beta}\right) ;
\end{array}\right.
$$

where:

$L$ - total phase inductance, $H$;

$M$ - mutual inductance of the stator and rotor phases, $H$;

Equation of the electromagnetic torque of an induction motor [15-16] is:

$$
\begin{aligned}
& T_{E M}=\frac{\sqrt{3}}{2} \cdot M \cdot p \cdot\left[\left(i_{s \alpha} \cdot i_{r \gamma}+i_{s \beta} \cdot i_{r \alpha}+i_{s \gamma} \cdot i_{r \beta}\right)-\right. \\
& \left.-\left(i_{s \alpha} \cdot i_{r \beta}+i_{s \beta} \cdot i_{r \gamma}+i_{s \gamma} \cdot i_{r \alpha}\right)\right] .
\end{aligned}
$$

Equation of motion for a motor shaft with a singlemass mechanical system reads:

$\frac{d \omega_{r}}{d t}=\frac{T_{E M}-T_{C}}{J}$

where:

$J$ - moment of inertia of rotating masses on the rotor shaft, $\mathrm{kg} \cdot \mathrm{m}^{2}$

$T_{C}$ - static torque on the rotor shaft, $N \cdot m$.

When modeling the operation of the induction motor, using Equations (1) - (4), certain difficulties may arise associated with stability of the model implementation algorithm. This is due to presence of a large number of integration operations in the algorithm. To reduce the number of integration operations, the number of differential equations should be reduced. For this purpose, it is necessary to express derivatives of the phase flux 
linkages in terms of the flux linkages themselves. To do this, one substitutes equations from system of Equations (2) into the system of equations (1). After the transformations, one gets [15]:

$$
\left\{\begin{array}{l}
\frac{d \psi_{s \alpha}}{d t}=z_{11} \cdot \psi_{s \alpha}+z_{12} \cdot \psi_{s \beta}+z_{13} \cdot \psi_{s \gamma}+ \\
+z_{14} \cdot \psi_{r \alpha}+z_{15} \cdot \psi_{r \beta}+z_{16} \cdot \psi_{r \gamma} ; \\
\frac{d \psi_{s \beta}}{d t}=z_{21} \cdot \psi_{s \alpha}+z_{22} \cdot \psi_{s \beta}+z_{23} \cdot \psi_{s \gamma}+ \\
+z_{24} \cdot \psi_{r \alpha}+z_{25} \cdot \psi_{r \beta}+z_{26} \cdot \psi_{r \gamma} ; \\
\frac{d \psi_{s \gamma}}{d t}=z_{31} \cdot \psi_{s \alpha}+z_{32} \cdot \psi_{s \beta}+z_{33} \cdot \psi_{s \gamma}+ \\
+z_{34} \cdot \psi_{r \alpha}+z_{35} \cdot \psi_{r \beta}+z_{36} \cdot \psi_{r \gamma} ; \\
\frac{d \psi_{r \alpha}}{d t}=z_{41} \cdot \psi_{s \alpha}+z_{42} \cdot \psi_{s \beta}+z_{43} \cdot \psi_{s \gamma}+ \\
+z_{44} \cdot \psi_{r \alpha}+z_{45} \cdot \psi_{r \beta}+z_{46} \cdot \psi_{r \gamma} ; \\
\frac{d \psi_{r \beta}}{d t}=z_{51} \cdot \psi_{s \alpha}+z_{52} \cdot \psi_{s \beta}+z_{53} \cdot \psi_{s \gamma}+ \\
+z_{54} \cdot \psi_{r \alpha}+z_{55} \cdot \psi_{r \beta}+z_{56} \cdot \psi_{r \gamma} ; \\
\frac{d \psi_{r \gamma}}{d t}=z_{61} \cdot \psi_{s \alpha}+z_{62} \cdot \psi_{s \beta}+z_{63} \cdot \psi_{s \gamma}+ \\
+z_{64} \cdot \psi_{r \alpha}+z_{65} \cdot \psi_{r \beta}+z_{66} \cdot \psi_{r \gamma} ;
\end{array}\right.
$$

where:

$z_{i j}$ - coefficients obtained as a result of conversion and which are functions of the total inductances and the mutual inductance of the stator and rotor phases, i.e. [15]:

$z=f(L, M)$

where:

$L$ - the total inductance of the corresponding stator or rotor phase, which is determined by formula [16]:

$L=L_{\sigma}+M$,

where:

$L_{\sigma}$ - leakage inductance of the corresponding stator or rotor phase, $H$.

The mutual inductance is determined by formula [16]:

$M=\frac{2}{3} \cdot L_{\mu}$,

where:

$L_{\mu}$ - magnetization inductance.

Then the equations for determining phase currents have the form [15]:
From the systems of Equations (3), (4), (5) and (8) a single system of differential equations of the first order is composed. Having solved this system in the MATHCad software environment, one obtains the value of the motor shaft rotation speed, electromagnetic torque, phase currents, which are needed for further calculations. In [15], realization of the mathematical model of the induction motor is given, made in the MATLab.

For an intact stator, first in the no-load mode, then in the nominal mode, values of the motor shaft speed, average, maximum and minimum electromagnetic torque and ripple frequency are determined by the model. Values of the current currents of the stator phases, angles of the lag of the phase currents of the stator from the voltages, currents of the rotor phases, angles of the rotor phase currents and voltages of the stator are determined, as well.

When organizing an asymmetrical mode, changes in the mutual inductance should be taken into account. To determine the change in the mutual inductances of the windings, it is necessary to determine what effect the change in the $\mathrm{AC}$ impedance of one winding (several windings) has on the magnetic circuit inductance. In [17], a relationship was established between the windings inductances and their geometric dimensions and the air gap was assumed to be uniform. Then, analyzing values of expressions for the phase inductances of the leakage and phase mutual inductances, one can conclude that the leakage inductance of each phase and the mutual phase inductances can be written in the general form:

$L_{i j}^{X Y}=\left(L^{\prime}\right)_{i j}^{X Y} \cdot F\left(\alpha_{i j}, \varphi_{i j}\right)$,

where:

$\left(L^{\prime}\right)_{i j}^{X Y}$ - component that depends on the winding geometric dimensions;

(superscripts $X, Y$ may take values $s$ or $r$ and show which windings are considered - stator $s$ or rotor $r$. Subscripts $i$, $j$ may take values $A, B, C$ and show which phase windings are considered);

$F\left(\alpha_{i j}, \varphi_{i j}\right)$ - component taking into account angular shifts between the phase voltages $\alpha_{i j}$ and the difference between the phase currents angular shifts of the stator and the rotor $\varphi_{i j}$ of the respective windings in a symmetrical mode.

Since the component $F\left(\alpha_{i j}, \varphi_{i j}\right)$ refers to the symmetric mode, one can restrict the considerations only $\left\{\begin{array}{l}i_{s \alpha}=u_{s a}-r_{s a} \cdot\left(a_{11} \cdot \psi_{s \alpha}+a_{12} \cdot \psi_{s \beta}+a_{13} \cdot \psi_{s \gamma}+a_{14} \cdot \psi_{r \alpha}+a_{15} \cdot \psi_{r \beta}+a_{16} \cdot \psi_{r \gamma}\right) \\ i_{s \beta}=u_{s \beta}-r_{s \beta} \cdot\left(a_{21} \cdot \psi_{s \alpha}+a_{22} \cdot \psi_{s \beta}+a_{23} \cdot \psi_{s \gamma}+a_{24} \cdot \psi_{r \alpha}+a_{25} \cdot \psi_{r \beta}+a_{26} \cdot \psi_{r \gamma}\right) ; \\ i_{s \gamma}=u_{s \gamma}-r_{s \gamma} \cdot\left(a_{31} \cdot \psi_{s \alpha}+a_{32} \cdot \psi_{s \beta}+a_{33} \cdot \psi_{s \gamma}+a_{34} \cdot \psi_{r \alpha}+a_{35} \cdot \psi_{r \beta}+a_{36} \cdot \psi_{r \gamma}\right) ; \\ i_{r \alpha}=-r_{r a} \cdot\left(a_{41} \cdot \psi_{s \alpha}+a_{42} \cdot \psi_{s \beta}+a_{43} \cdot \psi_{s \gamma}+a_{44} \cdot \psi_{r \alpha}+a_{45} \cdot \psi_{r \beta}+a_{46} \cdot \psi_{r \gamma}\right)+\frac{\left(\psi_{r \beta}-\psi_{r \gamma}\right) \cdot p \cdot \omega_{r}}{\sqrt{3}} ; \\ i_{r \beta}=-r_{r \beta} \cdot\left(a_{51} \cdot \psi_{s \alpha}+a_{52} \cdot \psi_{s \beta}+a_{53} \cdot \psi_{s \gamma}+a_{54} \cdot \psi_{r \alpha}+a_{55} \cdot \psi_{r \beta}+a_{56} \cdot \psi_{r \gamma}\right)+\frac{\left(\psi_{r \gamma}-\psi_{r \alpha}\right) \cdot p \cdot \omega_{r}}{\sqrt{3}} ; \\ i_{r \gamma}=-r_{s \gamma} \cdot\left(a_{61} \cdot \psi_{s \alpha}+a_{62} \cdot \psi_{s \beta}+a_{63} \cdot \psi_{s \gamma}+a_{64} \cdot \psi_{r \alpha}+a_{65} \cdot \psi_{r \beta}+a_{66} \cdot \psi_{r \gamma}\right)+\frac{\left(\psi_{r \alpha}-\psi_{r \beta}\right) \cdot p \cdot \omega_{r}}{\sqrt{3}} ;\end{array}\right.$ 


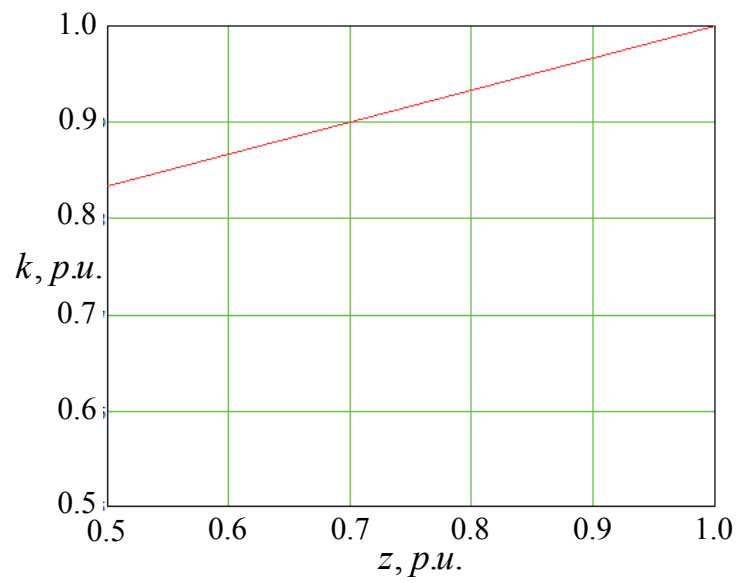

Figure 1 Dependence of the coefficient of change of the magnetic circuit inductance in terms of the $A C$ impedance change of the stator winding

to the component $\left(L^{\prime}\right)_{i j}^{X Y}$, which is equal to [17]:

$$
\left(L^{\prime}\right)_{i j}^{X Y}=l_{\beta} \cdot Z_{i}^{X} \cdot Z_{j}^{Y} \cdot \frac{\pi}{n^{2}} \cdot \frac{r_{r}^{3}}{g} \cdot \mu
$$

where:

$\mu$ - magnetic permeability;

$n$ - the number of periods of the spatial distribution of the current sheet, which, for an explicitly polar machine, corresponds to number of pairs of poles $p$;

$g=r_{s}-r_{r}$ - radial value of the air gap (subscripts show which windings are considered - stator $s$, rotor $r$ );

$r_{s}$ - stator radius;

$r_{r}$ - rotor radius;

$Z_{J}^{X}=\frac{W}{l}$ - linear density of the conductor of the corresponding winding current sheet;

$W_{j}^{X}$ - number of turns of the corresponding winding;

$l_{j}^{X}$ - length of the corresponding winding;

$l_{\beta}$ - axial air gap length.

The motor magnetic circuit inductance is determined by the expression [17]:

$$
L_{\mu}=\sum_{i} \sum_{j} L_{i j}^{X X}, X \neq Y \text {. }
$$

In Equation (12), one substitutes the value of inductances calculated using Equation (11) in a general form. The resulting equation is written in the form that corresponds to the form of a function of the winding number of turns, on which the change in the $\mathrm{AC}$ impedance is predicted during the inter-turn faults of various degrees. In Equation (12) one substitutes values of inductances calculated using Equation (11), taking into account the number of turns, which corresponds to a change in the $\mathrm{AC}$ impedance of the stator winding [15]:

$$
L_{\mu}^{\prime}=\sum_{i} \sum_{j}\left(L^{\prime}\right)_{i j}^{X X}, X \neq Y
$$

The resulting equation is presented in the form that corresponds to a function of the winding number of turns, on which a change in $\mathrm{AC}$ impedance is predicted.

Then, a coefficient, showing how the inductance of the magnetic circuit changes with a corresponding change in the AC impedance of the stator winding, is calculated as [15]:

$k=\frac{L_{\mu}^{\prime}}{L_{\mu}}$.

Using Equations (10) - (14), one calculates the coefficient of change in the magnetic circuit inductance from the change in the $\mathrm{AC}$ impedance of the stator winding, expressed in relative units and builds the dependence of this coefficient on the magnitude of the $\mathrm{AC}$ impedance change of the stator phase (Figure 1).

Using the value of the magnetic circuit inductance for the symmetric mode from Table 1, taking into account the coefficient, obtained using Equation (14) (Figure 1), one obtains value of the magnetic circuit inductance for the given conditions for the asymmetrical mode occurrence [15]:

$L_{\mu}^{\prime}=k \cdot L_{\mu}$.

Value of the magnetic circuit inductance, obtained using Equation (15) for the asymmetrical mode, is then substituted into Equation (8), thus, one obtains the mutual inductance value for the given mode.

After that, using Equation (7), the total phase inductances are determined. The results obtained are substituted into expressions for coefficients $z$, Equation (6). The resulting changes in parameters are adjusted on the simulation model. After that, the simulation model is ready for study of electromagnetic processes in an asynchronous motor with asymmetrical windings.

When organizing an asymmetrical mode, the following factors must be considered:

1. The most convenient parameter by which one can determine the inter-turn short circuit on one of the motor phases is the phase resistance.

2. As seen from Equation (11), both the phase leakage inductance and the mutual inductance are a function of the number of turns squared.

3. The active resistance of the winding is determined by expression: 
Table 2 Values of the of resistance, reactance, AC impedance of the stator phase and reactance of the mutual induction of the stator and rotor at different values of the $A C$ impedance

\begin{tabular}{ccccccc}
\hline$\frac{z_{1}}{z_{\text {1nom }}}$ & $z_{1}, \Omega$ & $w_{1}, p, u$. & $w_{1}^{2}, p, u$. & $r_{s}, \Omega$ & $x_{1}, \Omega$ & $x_{\mu}, \Omega$ \\
\hline 1 & 0.751 & 1 & 1 & 0.5 & 0.56 & 0.559 \\
0.9 & 0.676 & 0.934 & 0.872 & 0.467 & 0.489 & 0.547 \\
0.85 & 0.639 & 0.9 & 0.81 & 0.45 & 0.454 & 0.54 \\
0.8 & 0.601 & 0.864 & 0.746 & 0.432 & 0.418 & 0.534 \\
0.72 & 0.537 & 0.8 & 0.64 & 0.4 & 0.358 & 0.522 \\
\hline
\end{tabular}

$r_{s}=k_{r} \cdot \rho_{\theta} \cdot \frac{l_{\text {mean }} \cdot w}{q_{\text {e.c. }} \cdot n_{\text {e.c. }} \cdot a}$,

where:

$k_{r}$ - coefficient of increase in active resistance of the winding phase due to action of the current displacement effect; $\rho_{\theta}$ - material resistivity at design temperature, $\Omega \cdot m$;

$l_{\text {mean }}$ - average length of a winding turn, $m$;

$w$ - number of winding turns;

$q_{\text {e.c. }}$ - elementary conductor cross-sectional area, $m^{2}$;

$n_{\text {e.c. }}$ - number of elementary conductors;

$a$ - number of parallel winding branches.

In other words, the active resistance of the stator phase is a function of the winding turns number.

For convenience of transition from the impedance of the complex resistance $\frac{z_{1}}{z_{1 \text { nom }}}$ to resistance $r_{s}$, the inductive reactance's of the leakage inductance $x_{1}$ and the mutual inductance $x_{\mu}$, as functions of the number of turns $w$, Table 2 shows values of these quantities, which will be used in the future when studying the operation of an induction motor with asymmetrical stator windings.

\section{Investigation of the effect of the inter-turn short circuit on one of the stator phases of an asynchronousmotor on the ripple of the torque on the motor shaft and the unbalance of phase currents}

Here are now determined the values of similar parameters calculated for the symmetric mode, with a decrease in the phase resistance by $10 \%$ and $20 \%$, caused by the inter-turn faults (degree of fault). One determines those values with a decrease in the $\mathrm{AC}$ impedance of phase by $10 \%$ and $20 \%$. The simulation results are listed in Table 3 .

A motor shaft speed of $1500 \mathrm{rpm}$ cannot be obtained in practice for a four-pole asynchronous motor in the real no-load mode. During the computer simulation, using a rigid link that ensures the numerical equality of $T_{C}$ and $T_{E M}$ in each moment of time, realization of such a rotational speed is possible, if it is specified as the initial condition when integrating Equation (4). In the same way, one can simulate a mode of operation with any desired fixed speed value. In order to distinguish between the ideal no-load mode and the operating modes of the asynchronous motor with a load, the no-load speed, equal to $1500 \mathrm{rpm}$, was used when simulating.

In Table 3 , the torque pulsations are calculated by formula [16]:

$$
k_{p T}=\frac{T_{\max }-T_{\min }}{2 \cdot T_{\text {mean }}} \cdot 100 \%,
$$

where:

$T_{\max }$ - maximum torque, $N \cdot m$;

$T_{\min }$ - minimum torque, $N \cdot m$;

$T_{\text {mean }}$ - average torque, $N \cdot m$.

The stator current unbalance coefficient is determined by formula [16]:

$k_{i m b I}=\frac{I_{S \max }-I_{S \min }}{I_{\text {Ssym.mode }}} \cdot 100 \%$,

where:

$I_{S \max }$ - maximum stator phase current, $A$

$I_{\text {Smin }}$ - minimum stator phase current, $A$;

$I_{\text {Ssym,mode }}$ - phase current value in symmetrical mode, $A$.

Analysis of results of Table 3 shows that the moment ripple in the nominal mode is much less than the ripple of the no-load mode. Therefore, one builds dependences of the ripple coefficient of the electromagnetic moment on changes in the resistance and $\mathrm{AC}$ impedance of the stator phase $A$, only for the no-load operation (Figure 2, a)

According to results of Table 3 one constructs graphs of the unbalance coefficient of the stator phase currents depending on changes in the resistance and $\mathrm{AC}$ impedance of the stator phase $A$ for the no-load mode (Figure 2, b) and nominal mode (Figure 2, c)

As can be seen from Figure 2, the most significant changes occur with pulsation of the electromagnetic torque when the resistance and $\mathrm{AC}$ impedance of one of the phases change at the no-load. The unbalance coefficient of the stator phase currents changes insignificantly when both the resistance and $\mathrm{AC}$ impedance of one of the motor phases change. In addition, from Figure 2 it follows that both the torque ripple coefficient and the unbalance coefficient of the stator phase currents are more dependent on changes in the phase $\mathrm{A} A C$ impedance than on changes in the resistance.

\section{Investigation of the influence of inter-turn short circuit on mechanical and performance}

We will study the changes in the mechanical and operating characteristics of the motor in the event of an inter-turn short circuit at the stator phase, taking into 
Table 3 The simulation results for operation of an asynchronous motor in cases of absence and presence of the inter-turn short circuit

\begin{tabular}{|c|c|c|c|c|c|c|c|c|c|c|}
\hline \multirow{3}{*}{ parameter } & \multicolumn{5}{|c|}{ no-load mode } & \multicolumn{5}{|c|}{ rated mode } \\
\hline & \multirow{2}{*}{$\begin{array}{l}\text { intact } \\
\text { stator }\end{array}$} & \multicolumn{2}{|c|}{ resistance } & \multicolumn{2}{|c|}{ AC impedance } & \multirow{2}{*}{$\begin{array}{l}\text { intact } \\
\text { stator }\end{array}$} & \multicolumn{2}{|c|}{ resistance } & \multicolumn{2}{|c|}{$\mathrm{AC}$ impedance } \\
\hline & & $90 \%$ & $80 \%$ & $90 \%$ & $80 \%$ & & $90 \%$ & $80 \%$ & $90 \%$ & $80 \%$ \\
\hline rotation frequency, $n, r p m$ & 1500 & 1500 & 1500 & 1500 & 1500 & 1450 & 1450 & 1450 & 1450 & 1450 \\
\hline average electromagnetic torque $T_{\text {mean }}, N \cdot m$ & 0.38 & 0.381 & 0.382 & 0.381 & 0.382 & 72.443 & 72.8 & 74.4 & 72.6 & 72.88 \\
\hline max. electromagnetic torque $T_{\max }, N \cdot m$ & 0.38 & 0.799 & 1.236 & 1.513 & 1.9 & 72.443 & 73.709 & 76.261 & 74.149 & 74.938 \\
\hline min. electromagnetic torque, $T_{\min }, N \cdot m$ & 0.38 & -0.04 & -0.47 & 0.376 & -1.13 & 72.443 & 71.9 & 72.6 & 71.1 & 68.89 \\
\hline ripple frequency, $f_{\text {puls }}, H z$ & 0 & 100 & 100 & 100 & 100 & 0 & 100 & 100 & 100 & 100 \\
\hline RMS stator phase A current, $I_{1 A}, A$ & 9.4 & 9.583 & 9.762 & 10.36 & 11.56 & 21.879 & 21.8 & 22.6 & 23.4 & 25.57 \\
\hline RMS stator phase B current, $I_{1 B}, A$ & 9.4 & 9.379 & 9.371 & 9.486 & 9.814 & 21.879 & 21.3 & 21.7 & 20.7 & 20.29 \\
\hline RMS stator phase C current, $I_{1 C}, A$ & 9.4 & 9.253 & 9.099 & 9.959 & 9.981 & 21.879 & 21.1 & 21.1 & 21.8 & 20.32 \\
\hline $\begin{array}{l}\text { pulsation coefficient of electromagnetic } \\
\text { torque, } k_{\text {puls }}, \%\end{array}$ & 0 & 109.6 & 219.2 & 198.5 & 396.9 & 0 & 1.22 & 2.43 & 2.03 & 4.152 \\
\hline $\begin{array}{l}\text { stator phase current unbalance coefficient, } \\
k_{\text {puls } I_{1}}, \%\end{array}$ & 0 & 3.51 & 7.02 & 9.295 & 18.59 & 0 & 3.51 & 7.02 & 12.1 & 24.11 \\
\hline
\end{tabular}

Table 4 The dependence of the torque on the motor shaft $\left(T_{C}\right)$, net power $\left(P_{2}\right)$, The dependence of the reactive power, $\left(Q_{1}\right)$ the total power consumption of the network $\left(S_{1}\right)$ from motor shaft speed $(n)$, which must be provided

\begin{tabular}{cccccccccccccc}
\hline \multirow{2}{*}{$n, r p m$} & \multicolumn{3}{c}{$T_{C}, N \cdot m$} & \multicolumn{3}{c}{$P_{2}, W$} & \multicolumn{3}{c}{$Q_{1}, V \cdot A r$} & \multicolumn{3}{c}{$S_{1}, V \cdot A r$} \\
\hline 1425.7 & $100 \%$ & $90 \%$ & $80 \%$ & $100 \%$ & $90 \%$ & $80 \%$ & $100 \%$ & $90 \%$ & $80 \%$ & $100 \%$ & $90 \%$ & $80 \%$ \\
1440.8 & 83.132 & 83.623 & 84.133 & 12.54 & 12.617 & 12.694 & 8.585 & 9.347 & 9.49 & 16.554 & 17.129 & 17.391 \\
1450.0 & 72.443 & 72.641 & 72.878 & 11.0 & 11.03 & 11.066 & 7.513 & 7.019 & 8.301 & 14.44 & 14.319 & 15.128 \\
1470.8 & 42.923 & 43.03 & 43.137 & 6.611 & 6.628 & 6.644 & 6.528 & 7.226 & 7.32 & 9.803 & 10.351 & 10.485 \\
1485.8 & 20.573 & 20.573 & 20.573 & 3.201 & 3.201 & 3.201 & 6.137 & 6.643 & 6.782 & 7.091 & 7.568 & 7.726 \\
1488.3 & 16.727 & 16.727 & 16.727 & 2.607 & 2.607 & 2.607 & 6.123 & 6.505 & 6.678 & 6.782 & 7.162 & 7.355 \\
1490.8 & 12.824 & 12.824 & 12.824 & 2.002 & 2.002 & 2.002 & 6.121 & 6.515 & 6.822 & 6.527 & 6.931 & 7.257 \\
1493.3 & 8.793 & 8.793 & 8.793 & 1.375 & 1.375 & 1.375 & 6.237 & 6.521 & 6.929 & 6.447 & 6.747 & 7.171 \\
1494.8 & 6.458 & 6.458 & 6.458 & 1.012 & 1.012 & 1.012 & 6.204 & 6.555 & 6.988 & 6.333 & 6.694 & 7.138 \\
1496.4 & 3.8596 & 3.8596 & 3.8596 & 0.605 & 0.605 & 0.605 & 6.223 & 6.564 & 6.846 & 6.282 & 6.629 & 6.919 \\
1497.9 & 1.473 & 1.473 & 1.473 & 0.231 & 0.231 & 0.231 & 6.199 & 6.549 & 6.883 & 6.223 & 6.575 & 6.912 \\
1500 & 0 & 0 & 0 & 0 & 0 & 0 & 6.204 & 6.553 & 6.799 & 6.206 & 6.557 & 6.905 \\
\hline
\end{tabular}

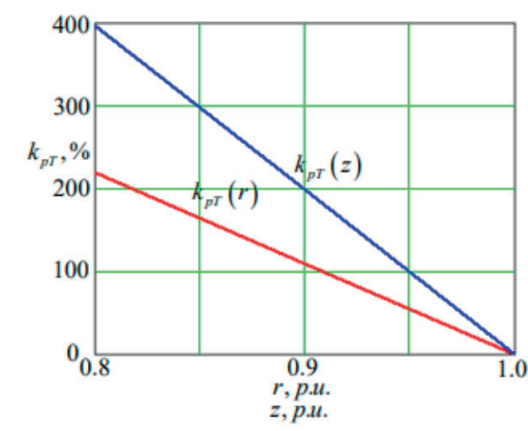

a)

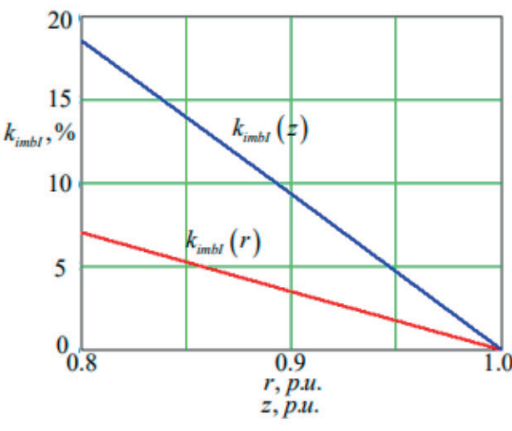

b)

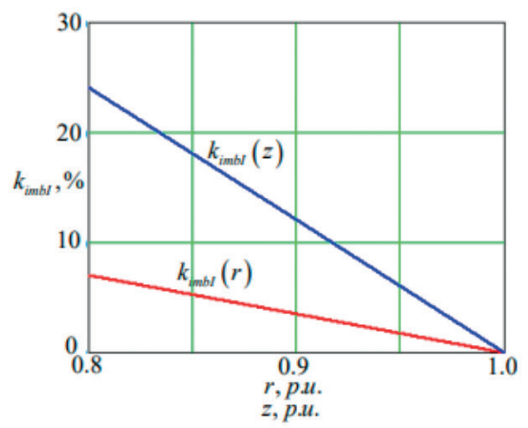

c)

Figure 2 Dependence of the ripple coefficient of the electromagnetic torque on change in the resistance of the stator phase in the no-load mode (a); the dependence of the unbalance coefficient of the stator phase currents on change in the stator phase resistance in the no-load mode (b) and rated mode $(c) .\left(k_{p T}, \%\right.$ - coefficient electromagnetic torque ripple; $k_{\text {imb.I }} \%$ - stator phase current unbalance; r,p.u. - stator resistance; $z$, p.u. - stator AC impedance) 
Table 5 Dependence of the average stator current $\left(I_{1 \text { mid }}\right)$, active power consumed from the network $\left(P_{1}\right)$, efficiency $(\eta)$, power factor $(\gamma)$ on the motor shaft speed $(n)$, which must be provided

\begin{tabular}{ccccccccccccc}
\hline \multirow{2}{*}{$n, r p m$} & \multicolumn{3}{c}{$I_{1 \text { mid }} A$} & \multicolumn{3}{c}{$P_{1}, W$} \\
\cline { 2 - 14 } & $100 \%$ & $90 \%$ & $80 \%$ & $100 \%$ & $90 \%$ & $80 \%$ & $100 \%$ & $90 \%$ & $80 \%$ & $100 \%$ & $90 \%$ & $80 \%$ \\
\hline 1425.7 & 30.71 & 31.75 & 32.149 & 17.309 & 17.519 & 17.739 & 0.87 & 0.864 & 0.857 & 0.854 & 0.845 & 0.836 \\
1440.8 & 25.082 & 25.953 & 26.351 & 14.153 & 14.543 & 14.574 & 0.886 & 0.879 & 0.836 & 0.855 & 0.847 & 0.838 \\
1450.0 & 21.879 & 21.969 & 22.058 & 12.332 & 12.481 & 12.647 & 0.892 & 0.884 & 0.875 & 0.854 & 0.845 & 0.836 \\
1470.8 & 14.853 & 15.683 & 15.887 & 7.313 & 7.411 & 7.507 & 0.904 & 0.895 & 0.885 & 0.746 & 0.731 & 0.716 \\
1485.8 & 10.744 & 11.467 & 11.706 & 3.553 & 3.625 & 3.701 & 0.901 & 0.883 & 0.865 & 0.501 & 0.49 & 0.479 \\
1488.3 & 10.275 & 10.852 & 11.143 & 2.916 & 2.997 & 3.082 & 0.894 & 0.87 & 0.846 & 0.43 & 0.418 & 0.419 \\
1490.8 & 9.989 & 10.502 & 10.996 & 2.265 & 2.364 & 2.475 & 0.884 & 0.847 & 0.809 & 0.347 & 0.344 & 0.341 \\
1493.3 & 9.768 & 10.223 & 10.865 & 1.631 & 1.73 & 1.846 & 0.843 & 0.795 & 0.745 & 0.253 & 0.242 & 0.227 \\
1494.8 & 9.596 & 10.142 & 10.845 & 1.273 & 1.358 & 1.456 & 0.795 & 0.745 & 0.695 & 0.201 & 0.203 & 0.204 \\
1496.4 & 9.518 & 10.044 & 10.484 & 0.861 & 0.926 & 1.003 & 0.703 & 0.653 & 0.603 & 0.137 & 0.14 & 0.145 \\
1497.9 & 9.429 & 9.962 & 10.473 & 0.547 & 0.586 & 0.628 & 0.419 & 0.394 & 0.368 & 0.078 & 0.089 & 0.081 \\
1500 & 9.403 & 9.935 & 10.467 & 0.156 & 0.221 & 0.285 & 0 & 0 & 0 & 0.025 & 0.034 & 0.041 \\
\hline
\end{tabular}

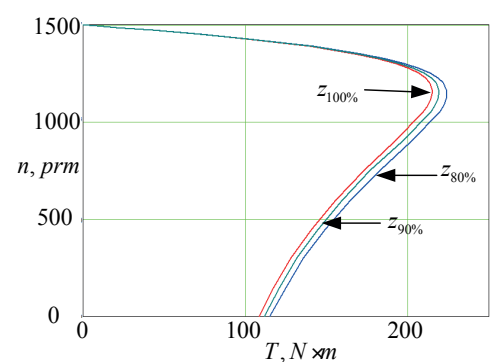

a)

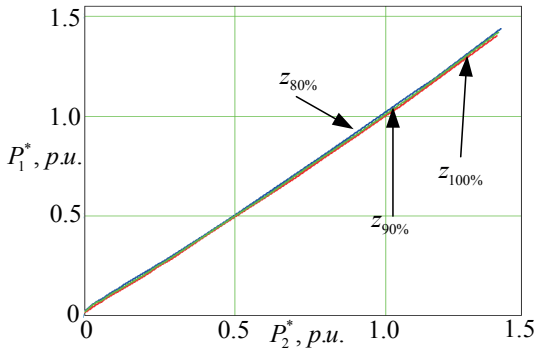

b)

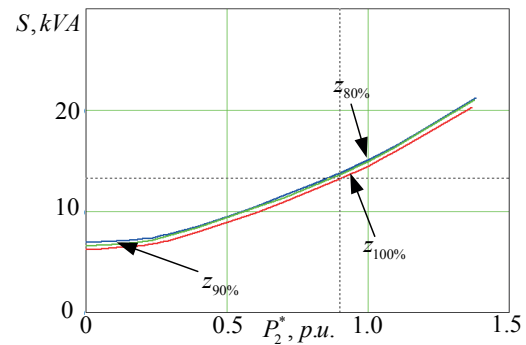

c)

Figure 3 Dependence of the rotational speed of the motor shaft $(n)$ on the motor shaft torque $(T)$ (a); dependence of the relative value of the active power consumed from the network $\left(P_{1}^{*}=P_{1} / P_{1 r}\right)(b)$; the dependence of the total power consumed on the network $(S) ;(c)$ on the relative value of the net power $\left(P_{2}^{*}=P_{2} / P_{2 r}\right)$

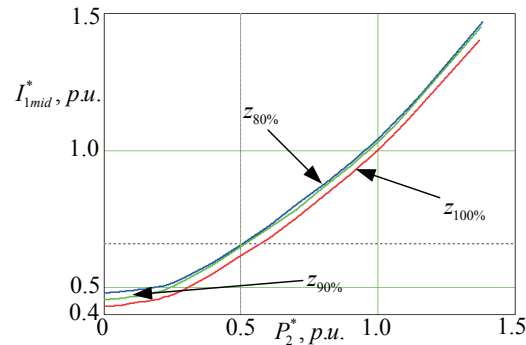

a)

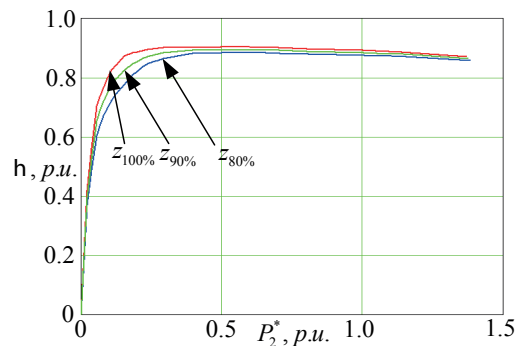

b)

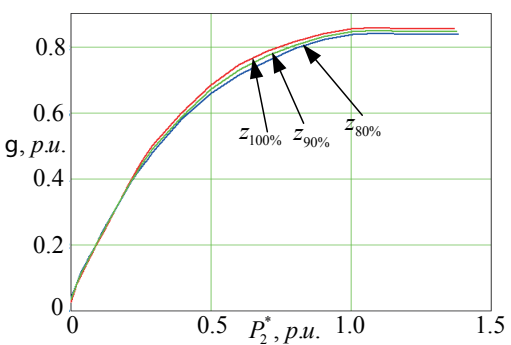

c)

Figure 4 The relative value of the average stator current $\left(I_{1 \text { mid }}=I_{1} / I_{1 r}\right)(a)$; the dependence of efficiency $(\eta)(b)$ and power factor $(\gamma) ;(c)$ on the relative value of the net power $\left(P_{2}^{*}=P_{2} / P_{2 r}\right)$

account that $10 \%$, then $20 \%$ of the turns of this winding were closed first. We assume that as a result of the inter-turn circuit, first $10 \%$, then $20 \%$ of the turns, the AC impedance of the stator winding in this model has changed.

We model these processes on a simulation model. Modeling will be performed by fixing the rotation speed of the motor shaft, using $T_{C}=T_{E M}$ equation. The simulation results are entered in Tables 4, 5. Modeling will be carried out for $100 \%, 90 \%$ and $80 \%$ of the relative AC impedance of stator.
The net power is determined by [16]:

$$
P_{2}=T_{C} \cdot \omega_{r}
$$

Motor shaft mechanical speed is:

$\omega_{r}=\frac{\pi \cdot n}{30}$

where:

$n$ - motor shaft mechanical speed, rpm. 
Instantaneous reactive power is determined by [16]:

$$
Q_{1}=-\frac{1}{\sqrt{3}} \cdot\left(\begin{array}{l}
u_{s \alpha} \cdot\left(i_{s \beta}-i_{s \gamma}\right)+u_{s \beta} \cdot\left(i_{s \gamma}-i_{s \alpha}\right)+ \\
+u_{s \gamma} \cdot\left(i_{s \alpha}-i_{s \beta}\right)
\end{array}\right)
$$

Instantaneous active power is determined by [16]:

$$
P_{1}=u_{s \alpha} \cdot i_{s \alpha}+u_{s \beta} \cdot i_{s \beta}+u_{s \gamma} \cdot i_{s \gamma}
$$

Then, the value of the instantaneous total power, consumed from the network, can be determined as:

$$
S_{1}=\sqrt{\left(P_{1}\right)^{2}+\left(Q_{1}\right)^{2}} \text {. }
$$

The average current in the stator phase, in the case of asymmetrical stator windings is determined by [16]:

$$
I_{1 m i d}=\frac{I_{1 A}+I_{1 B}+I_{1 C}}{3} .
$$

The efficiency is given by [16]:

$$
\eta=\frac{P_{2}}{P_{1}}
$$
[16]:

The power factor can be determined using expression

$$
\gamma=\frac{P_{1}}{S_{1}}
$$

According to results of Table 3, one constructs the mechanical characteristic (Figure 3, a). According to results of Tables 3 and 4 , one constructs dependence of the relative value of the active power consumed from the network on the relative value of the useful power (Figure 3, b), the dependences of the total power consumed from the network (Figure 3, c).

According to results of Tables 4 and 5, one builds dependences of the relative value of the average stator current (Figure 4, a), the efficiency coefficients (Figure 4, b) and power (Figure $4, \mathrm{c}$ ) on the relative value of the useful power.

Figures 3-4 show that with an increase in the degree of inter-turn short circuit:

- $\quad$ value of the critical torque increases (Figure 3, a);

- increases the active (Figure 3, b) and the total power consumed from the network (Figure 3, c);
- the average value of the stator current increases (Figure 4, a);

- the efficiency value decreases (Figure 4, b) and the motor power factor (Figure 4, c).

\section{Conclusions}

The article proposes an integrated approach to study of the inter-turn short circuit effect on parameters and characteristics of asynchronous motors. To solve this problem, the following was accomplished:

- A mathematical model of an asynchronous motor was selected, which allows you to simulate operation of an asynchronous motor with asymmetrical windings. A method is proposed for organizing the asymmetry of stator windings, taking into account the change in mutual inductance.

- The effect of inter-turn fault in the winding of one of the stator phases on the ripple factor of the electromagnetic torque and the unbalance coefficient of the stator phase currents has been investigated. The research results showed that the greatest value of the ripple factor of the torque is in the no-load mode when the AC impedance changes (at 20\% inter-turn short circuit, the ripple factor of the torque was 264\%). The stator phase current unbalance coefficient is also greater when the $\mathrm{AC}$ impedance changes, but it has close values for the no-load mode and for nominal mode ( $16.5 \%$ for the no-load mode and $16.2 \%$ for the nominal mode).

- Studies of effect of inter-turn short circuit on mechanical characteristics showed that when the inter-turn short circuit is increased to $20 \%$, the critical torque of the motor increases by $2 \%$, which is also accompanied by an increase in the starting torque of the motor.

- Studies have shown that with a nominal motor operating mode the same increase in inter-turn short circuit leads to an increase in the total power consumed from the network by $7.1 \%$, active - by $4.2 \%$, average stator phase current - by $7.2 \%$. This, in turn, leads to a decrease in the efficiency factor of $4.78 \%$, power factor - by $3.2 \%$.

This work can be used to select an effective method for diagnosing the inter-turn faults in the stator winding when constructing a diagnostic system for asynchronous motors as a part of drives of the transport equipment.

\section{References}

[1] MERIZALDE, Y., HERNANDEZ-CALlEJO, L., DUQUE-PEREZ, O. State of the art and trends in the monitoring, detection and diagnosis of failures in electric induction motors. Energies [online]. 2017, 10(7), 1056. eISSN $1996-1073$. Available from: https://doi.org/10.3390/en10071056

[2] MAIRTE, J., GABOURY, S., BOUCHARD, B., BOUZOUANE, A. A new computational method for stator faults recognition in induction machines based on hyper-volumes. In: IEEE International Conference on Electro/Information Technology EIT 2015: proceedings [online]. IEEE. 2015. ISSN 2154-0357, p. 216-220. Available from: https://doi.org/10.1109/ EIT.2015.7293343 
[3] BELYAYEV, P. V., GOLOVSKIY, A. P. Damage to the stator winding of asynchronous motor and their diagnostics (in Russian). Young Russia: Advanced Technologies -in Industry! [online]. 2019, 1. p. 33-37. ISSN 2310-9793. Available from: https://doi.org/10.25206/2310-4597-2019-1-33-37

[4] PIETROWSKI, W., GORNY, K. Detection of inter-turn short-circuit at start-up of induction machine based on torque analysis. Open Physics [online]. 2017, 15(1), p. 851-856. eISSN 2391-5471. Available from: https://doi.org/10.1515/phys2017-0101

[5] CIRA, F., ARKAN, M., GUMUS, B. Detection of stator winding inter-turn short circuit faults in permanent magnet synchronous motors and automatic classification of fault severity via a pattern recognition system. Journal of Electrical Engineering and Technology. [online]. 2016, 11(2), p. 416-424. ISSN 2093-7423. Available from: http://dx.doi.org/10.5370/JEET.2016.11.1.1921

[6] ZAGIRNYAK, M., KALINOV, A., MELNYKOV, V., STACHIN, P. Fault-tolerant control of an induction motor with broken stator electric circuit. In: Electric Power Networks EPNet: proceedings [online]. IEEE. 2016. ISBN 978-1-5090-5518-0, p. 1-6. Available from: https://doi.org/10.1109/EPNET.2016.7999372

[7] GOAZZELLI, P. R. U., DE ANDRADE PEREIRA, W. C., DE OLIVEIRA, C. M. R., DE CASTRO, A. G., DE AGUIAR, M. L. Weighting factors optimization of predictive torque control of induction motor by multiobjective genetic algorithm. IEEE Transactions on Power Electronics [online]. 2018, 34(7), p. 6628-6638. ISSN 1941-0107. Available from: https://doi.org/10.1109/TPEL.2018.2834304

[8] MAHMOUD, H., ABDAllh, A. A. E., BIANCHI, N., El-HAKIM, S. M., SHAltouT, A., DUPRE, L. An inverse approach for interturn fault detection in asynchronous machines using magnetic pendulous oscillation technique. IEEE Transactions on Industry Applications [online]. 2015, 52(1), p. 226-233. ISSN 1939-9367. Available from: https://doi.org/10.1109/TIA.2015.2478882

[9] WELLINTON, P., DE MENDONCA ROBERLAM, G., LUCIANO, M. N. Comparative performance analysis of a standard three-phase induction motor and an asymmetric three-phase induction motor fed from a single-phase network. Electric Power Systems Research [online]. 2015, 125, p. 211-219. ISSN 0378-7796. Available from: https://doi.org/10.1016/j. epsr.2015.02.016

[10] GUESMI, H., SALEM, S. B., BACHA, K. Smart wireless sensor networks for online faults diagnosis in induction machine. Computers and Electrical Engineering [online]. 2015, 41, p. 226-239. ISSN 0045-7906. Available from: https://doi.org/10.1016/j.compeleceng.2014.10.015

[11] DONOlO, P., BOSSIO, G., De ANGElO, C., GARCIA, G., DONOLO, M. Voltage unbalance and harmonic distortion effects on induction motor power, torque and vibrations. Electric Power Systems Research [online]. 2016, 140, p. 866-873. ISSN 0378-7796. Available from: https://doi.org/10.1016/j.epsr.2016.04.018

[12] ALSAEDI, M. A. Fault diagnosis of three-phase induction motor: a review. Optics [online]. 2015, 4(1-1), p. 1-8. ISSN 2328-7810. Available from: https://doi.org/10.11648/j.optics.s.2015040101.11

[13] KUMAR, N., CHELLIAH, T. R., SRIVASTAVA, S. P. Analysis of doubly-fed induction machine operating at motoring mode subjected to voltage sag. Engineering Science and Technology, an International Journal [online]. 2016, 19(3), p. 1117-1131. ISSN 2215-0986. Available from: https://doi.org/10.1016/j.jestch.2016.01.015

[14] JANDA, M., JANDOVA, K. Vibration Simulation of Electric Machines. In: Finite Element Method-Simulation, Numerical Analysis and Solution Techniques [online]. IntechOpen, 2017. ISBN 978-953-51-3849-5, eISBN 978-953-51-3850-1, p. 193-204. Available from: https://doi.org/10.5772/intechopen.72266

[15] GOOLAK, S., GUBAREVYCH, O., YERMOLENKO, E, SLOBODYANYUK, M, GOROBCHENKO, O. Development of mathematical model of induction motor for vehicles. Eastern-European Journal of Enterprise Technologies [online]. 2020, 2/2(104), p. 24-35. ISSN 1729-3774, eISSN 1729-4061. Available from: https://doi.org/10.15587/17294061.2020.199559

[16] PUSTOVETOV, M. Y. Approach to computer implementation of mathematical model of 3-phase induction motor. IOP Conference Series: Materials Science and Engineering [online]. 2018, 327(2), 022085. ISSN 1757-8981, eISSN 1757-899X. Available from: https://doi.org/10.1088/1757-899X/327/2/022085

[17] GOOLAK, S., GERLICI, J., SAPRONOVA, S., TKACHENKO, V., LACK, T., KRAVCHENKO, K. Determination of parameters of asynchronous electric machines with asymmetrical windings of electric locomotives. Communications - Scientific Letters of the University of Zilina [online]. 2019, 21(2), p. 24-31. ISSN 1335-4205, eISSN 2585-7878. Available from: https://doi.org/10.26552/com.C.2019.2.24-31 